\title{
THE
}

\section{Microplastics are not important for the cycling and bioaccumulation of organic pollutants in the oceans - but should microplastics be considered POPs themselves?}

Rainer Lohmann

University of Rhode Island, rlohmann@uri.edu

Follow this and additional works at: https://digitalcommons.uri.edu/gsofacpubs

The University of Rhode Island Faculty have made this article openly available.

Please let us know how Open Access to this research benefits you.

This is a pre-publication author manuscript of the final, published article.

Terms of Use

This article is made available under the terms and conditions applicable towards Open Access

Policy Articles, as set forth in our Terms of Use.

\section{Citation/Publisher Attribution}

Lohmann, Rainer. Microplastics are not important for the cycling and bioaccumulation of organic pollutants in the oceans - but should microplastics be considered POPs themselves? Integr Env Assess Monit 2017, 13, 460-465.

Available at: http://dx.doi.org/10.1002/ieam.1914

This Article is brought to you for free and open access by the Graduate School of Oceanography at DigitalCommons@URI. It has been accepted for inclusion in Graduate School of Oceanography Faculty Publications by an authorized administrator of DigitalCommons@URI. For more information, please contact digitalcommons-group@uri.edu. 
1 Microplastics are not important for the cycling and bioaccumulation of organic pollutants

2 in the oceans - but should microplastics be considered POPs themselves?

3 by Rainer Lohmann

4

5 Graduate School of Oceanography, University of Rhode Island, Narragansett, Rhode Island $6 \quad$ 02882-1197, United States.

7 Email: rlohmann@uri.edu

8

9 Background

10 This commentary discusses the current evidence about current prevailing themes on the

11 relationship between marine microplastics and organic pollutants. In this context, microplastics

12 can be defined as particles $<5 \mathrm{~mm}$ in size [Thompson et al., 2004]. This plastic debris, mostly

13 from anthropogenic land-based sources, fragments into smaller pieces over time [Jambeck et al., 14 2015].

15

16 Do microplastics accumulate high concentrations of organic pollutants.

17 The current body of evidence suggests that this is true, as microplastics act - as do polymers in

18 general - as passive samplers of organic pollutants. The specific affinity of a given organic

19 pollutant for a polymer dictates its overall enrichment factor (partitioning constant) in the

20 microplastic [Rusina et al., 2007]. The specific affinity for various hydrophobic organic

21 contaminants (HOCs) for polymers has been determined in numerous laboratory and field

22 calibrations in which the partitioning constants between passive samplers and water or air were

23 measured [Adams et al., 2007; Rusina et al., 2007; Smedes et al., 2009; Lohmann, 2012; 
24 Pintado-Herrera et al., 2016; Ziccardi et al., 2016]. The polymers most commonly used as

25 passive samplers in field experiments include polyethylene (PE), silicone rubber (SR) and

26 polyoxymethylene (POM) sheets.

27 There is also plenty of field evidence showing that generic plastic debris accumulates organic pollutants [Karapanagioti et al., 2011; Rochman et al., 2012; Endo et al., 2013]. A prominent example is the so-called 'pellet watch' global monitoring program, which relies on plastic pellets collected by volunteers from across the globe [Hirai et al., 2011]. In these studies, strong enrichment of HOCs in the polymers, often exceeding $10^{6}$ times relative to their dissolved concentrations was found. POPs?

It has become common knowledge that microplastics are present around the globe, and have been found in all ocean gyres, coastal seas and beaches [Jambeck et al., 2015; Sebille et al., 2015]. It should therefore be no surprise that the concept of microplastics as being important for the global dispersion of organic pollutants, in particular persistent organic pollutants (POPs), a subgroup of persistent HOCs, has been suggested. Yet, numerous studies have refuted that idea

41 [Zarfl and Matthies, 2010; Gouin et al., 2011; Koelmans et al., 2016; Ziccardi et al., 2016].

42 There is simply not enough microplastic and plastic debris present in the oceans to outcompete

43 the partitioning of POPs to water and natural organic matter (such as phytoplankton). In

44 Koelman et al. [2016]'s analysis of a strongly HOC (concentrated $10^{7}$ times from water), ocean water nonetheless contained $99 \%$ of the HOC, followed by DOC and colloids $(0.4 \%$ each); microplastics captured $\sim 10^{-4} \%$ of the total mass present in the oceans. 
47 In addition, diffusion of HOCs in and out of microplastics is slow. The time for various dissolved polychlorinated biphenyls (PCBs) to reach equilibrium with a $50 \mu \mathrm{m}$ or $500 \mu \mathrm{m}$ PE sheet ranges

49 from days to decades [Lohmann and Muir, 2010; Endo et al., 2013]. Thus the release of these contaminants from the microplastic present in the remote ocean will be strongly retarded [Endo et al., 2013; Bakir et al., 2014b] and only add a small contribution relative to already present POPs at any given place and time. Results by Zarfl and Matthies [2010] also implied that microplastics are not an efficient transport vector of HOCs in comparison to long range transport by ocean or atmosphere, except for very high $\log \mathrm{K}_{\mathrm{ow}}$ chemicals, which have otherwise limited transport potential in air and water.

Lastly, a comparison of microplastic particle density in the Pacific Ocean as detected by the Sea Education Association (SEA; Lavender-Law, personal communication) and measured concentrations of PCBs in surface seawater in the region [Zhang and Lohmann, 2010] found 59 little correlation between both.

To what extent to microplastics contribute to the bioaccumulation and foodweb transfer of POPs?

64 efficient carriers of organic pollutants into biota and the foodweb [Teuten et al., 2009; Rochman et al., 2013; Chua et al., 2014; Batel et al., 2016; Wardrop et al., 2016]. Such arguments have

66 been based on the notion that microplastics enrich various POPs (correct, see above), coupled

67 with the assumption that inside an animal, these pollutants are stripped off or leach out of the 68 microplastic and are taken up by the organism (e.g.,[Teuten et al., 2007; Bakir et al., 2014a]). It 69 is worth recalling that chemicals diffuse to achieve the same chemical activity in the 
environment, be that water, microplastic or biota [Schwarzenbach et al., 2003]. Just because microplastics display greater concentrations of POPs than present in water does not mean that

72 there is a greater tendency for these pollutants to diffuse out of the plastic particles. The potential

73 importance of microplastics as carriers of POPs into animals remains a strong theme in

74 discussion on microplastics, though, seemingly corroborated by empirical evidence [Teuten et 75 al., 2009], it requires deeper examination. This will be addressed in more detail below using the 76 three scenarios outlined in Figure 1, in which (a) a naturally contaminated fish ingests a naturally

77 contaminated microplastic (e.g., both collected in the wild); (b) a clean fish consumes a

78 contaminated microplastic particle (e.g., in laboratory experiments), and (c) a reverse set-up,

79 where a contaminated fish consumes a pollutant-free microplastic particle. Examples from the

80 literature supporting these different scenarios are listed in Table 1._At a very basic level,

81 equilibrium partitioning thinking can be used to define simple expectations in which way organic

82 pollutants will move in a bioaccumulation thought experiment.

84 Scenario A

As outlined in scenario a) (Figure 1) a fish and piece of microplastic both contain POPs already, simply from occurring in the environment. The presence of POPs in the fish, and a

87 microplastic residing in the same environment, are driven by the contaminants' chemical activity and ought to be the same in both fish and microplastic particles. The ingestion of the

89 microplastic by the fish does not change the contaminant burden by the fish or the microplastic, as they are both already in equilibrium [Gouin et al., 2011]. This should be the most prevalent

91 interaction of biota, microplastics, and POPs in the natural environment, as animals are

92 constantly taking up POPs from the environment via their diet and respiration. There are neither 
93 clean (i.e., POPs-free) oceans nor animals present, which means that they will bioaccumulate

94 POPs regardless of whether they ingest microplastics or not.

95 In the South Atlantic Ocean, there was generally no correlation between HOCs in microplastics

96 and amphipods [Rochman et al., 2014]. Of the targeted HOCs (bisphenol A (BPA), alkylphenols,

97 alkylphenol ethoxylates, PCBs, and polybrominated diphenyl ethers (PBDEs)), only PBDEs

98 displayed increased body burdens in regions where more microplastics were present. The

99 presence of PBDEs in tissues could be due to the presence of small microplastic particles during

100 the extraction (see below). Another good example of scenario of (a) is the recent study in which

101 birds and the microplastics in their gut were analyzed for PCBs [Herzke et al., 2016]. The

102 authors concluded that the presence of PCBs in the fulmars due to the ingestion of plastics was

103 negligible relative to the uptake of PCBs via their prey.

104 Similar conclusions were reached earlier by Gouin et al. (2011) based on theoretical

105 considerations based on a bioaccumulation food web model. Lastly, Koelmans et al. (2016) also

106 concluded that there is no experimental or theoretical evidence for an important role of

107 microplastics in the transfer of POPs into animals.

108

109 Scenario B

110 This scenario consists of exposing clean animals from a reference site to microplastics

111 containing a high concentration of POPs, either from laboratory dosing or from microplastics

112 exposed to contaminants at urban/industrialized sites. Most reported bioaccumulation studies

113 with microplastics are based on this scenario, such as the ingestion of PBDE-spiked particles by

114 amphipods in the laboratory [Chua et al., 2014]. Interestingly, the experiment actually resulted in

115 decreased PBDE bioaccumulation uptake relative to control animals. Other experiments used 
116 field-contaminated microplastic particles. For example, Teuten et al. (2009) described the

117 feeding of microplastics naturally contaminated by PCBs from Tokyo Bay to shearwater chicks

118 hidden in a fish diet. Initially, some uptake of lower chlorinated PCBs was observed, but the

119 PCBs ingested from the bird's prey fish outweighed the birds' body burden over time [Teuten et

120 al., 2009].

121 In general, an efficient transfer of POPs from the microplastic to the animals is observed. This is

122 due to the experimental design, and shows that microplastic can be used as a vector for POPs

123 into animals. It does not demonstrate, however, that this pathway is relevant in the field. As

124 noted above, animals in the wild are typically as 'contaminated' with respect to POPs as the

125 microplastic particles they might consume. The conclusion that microplastics is not an important

126 transfer process was also reached in a study exposing lugworms to sediments enriched with field-

127 contaminated polystyrene particles [Besseling et al., 2013]. The observed increase in PCB

128 bioaccumulation ( $1.1-1.5$ times relative to controls) was only observed at low concentrations of 129 polystyrene particles.

131 Scenario C

132 This scenario is the reverse of scenario b) in which a POP-contaminated fish is fed clean

133 microplastic to determine if this will lower its body burden with respect to the POP. The idea is

134 based on research that olestra, a non-digestible fat, can be used to remove POPs from

135 contaminated animals [Moser and McLachlan, 1999]. Gouin et al. (2011) picked up this idea in

136 their bioaccumulation model, suggesting that the ingestion of clean microplastic could indeed

137 cause a decreased body burden in animals. Recently, Rummel et al. (2016), did not observe a 
138 significant decrease in bioaccumulation of PCBs in rainbow trout allowed to ingest clean 139 microplastics.

141 Do microplastics transfer other organic contaminants into biota?

142 As discussed above, there is little evidence that microplastics play a major role in the

143 bioaccumulation of POPs, when compared to the role of diet in nature. As already discussed by

144 [Teuten et al., 2009] and [Gouin et al., 2011], microplastics could become an important pathway

145 for polymer additives that otherwise would not be easily transferred into the marine environment.

146 In particular, [Teuten et al., 2009] suggested research should focus on the release of phenolic

147 additive-derived chemicals (i.e., alkylphenols and BPA) from microplastics in the food web. Yet

148 neither a modeling study by [Koelmans et al., 2014] nor the field study by [Rochman et al.,

149 2014] found evidence that the ingestion of microplastics is relevant for the uptake of these

150 compounds by biota.

151 Several recent studies highlighted that certain chemicals, likely originating from plastic particles, 152 can indeed be transferred into animals. The presence of highly brominated BDEs 183 and 209 in 153 seabirds was linked to their ingestion of marine plastics [Tanaka et al., 2013]. The birds' prey 154 items had no detectable BDE 183 and 109 concentrations but these contaminants were observed 155 in both the birds and ingested plastic debris particles. Similarly, the presence of

156 hexabromocyclododecanes (HBCDs) in Styrofoam and blue mussels from coastal South Korea 157 were linked [Jang et al., 2016]. Elevated concentrations, and a $\alpha / \gamma \mathrm{HBCD}$ ratio closer to that of 158 Styrofoam were detected in mussels colonizing Styrofoam buoys, when compared to mussels 159 collected from other substrates and regions along the coast. Overall, strong evidence was 
presented for a direct pathway of HBCD from the Styrofoam buoy into the mussel, including the detection of Styrofoam particles in the mussels themselves.

162 As there is good evidence that brominated compounds can be metabolized in animals [Stapleton 163 et al., 2004], the presence of several low solubility brominated compounds (highly brominated 164 BDEs, HBCD) in biota, linked to the ingestion of microplastics, seems surprising at first. Yet it 165 might actually indicate that these compounds are not properly dissolved in the animals, but rather part of nanoplastic particles dispersed within the animals' tissue and organs.

\section{Should microplastics be considered POPs?}

169 While the preceding discussion highlighted that microplastics in the oceans do little to affect the 170 presence and transfer of most organic pollutants at this point, there is still plenty of evidence that 171 microplastics are harmful and their impact should be minimized, as far as possible. This be could 172 be seen as a contribution towards a sustainable use of resources.

173 One approach would be to consider classifying microplastics as potential pollutants under the

174 Stockholm Convention on POPs [UNEP, 2001]. Four criteria, namely persistence,

175 bioaccumulation, long-range transport and adverse effects (Table 2), must be met for a 176 compound to be listed as a POP. There is strong evidence that microplastics are persistent, as a 177 result of their industrial polymer properties and additives [Gewert et al., 2015], and that they 178 undergo long-range transport, as documented by their widespread presence in remote oceans 179 [Lavender Law et al., 2010; Sebille et al., 2015]. Several ecotoxicologial studies highlight 180 adverse effects, though these experiments are often performed at unrealistically high doses of 181 microplastic exposure. The classical concept of bioaccumulation and biomagnification on a 
molecular level is not met, but there is evidence that microplastics are present in top predators and are transferred up the food chain.

In summary, there is little evidence that marine microplastics affect the global transport or bioaccumulation of POPs in the oceans. In terms of bioaccumulation, experimental designs can be manipulated to show that microplastics are a vector of POPs into organisms in the laboratory. Yet, there is scant evidence from field studies that the ingestion of microplastics affects the bioaccumulation of POPs. While there are some studies that show several low-solubility compounds increase in animals that have ingested more microplastics, this might in fact be from the presence of micro- and nanoplastic particles in those animals. Just because microplastics are not relevant for the transport of POPs does not take away from their potential for detrimental impacts on the environment. A possibility to address these concerns could be to consider marine (micro)plastics as POPs, and rely on the Stockholm Convention to reduce their sources.

\section{References}

Adams, R. G., R. Lohmann, L. A. Fernandez, J. K. MacFarlane, and P. M. Gschwend (2007), Polyethylene devices: Passive samplers for measuring dissolved hydrophobic organic compounds in aquatic environments, Environ. Sci. Technol., 41(4), 1317-1323, doi:10.1021/es0621593.

Bakir, A., S. J. Rowland, and R. C. Thompson (2014a), Enhanced desorption of persistent organic pollutants from microplastics under simulated physiological conditions, Environ. Pollut., 185, 16-23, doi:10.1016/j.envpol.2013.10.007.

Bakir, A., S. J. Rowland, and R. C. Thompson (2014b), Estuarine, Coastal and Shelf Science Transport of persistent organic pollutants by microplastics in estuarine conditions, Estuar. Coast. Shelf Sci., 140, 14-21, doi:10.1016/j.ecss.2014.01.004.

Batel, A., F. Linti, M. Scherer, L. Erdinger, and T. Braunbeck (2016), Transfer of benzo[a]pyrene from microplastics to Artemia Nauplii and further to zebrafish via a trophic food web experiment: CYP1A induction and visual tracking of persistent organic pollutants, Environ. Toxicol. Chem., 35(7), 1656-1666, doi:10.1002/etc.3361.

Besseling, E., A. Wegner, E. M. Foekema, M. J. Van Den Heuvel-Greve, and A. A. Koelmans (2013), Effects of Microplastic on Fitness and PCB Bioaccumulation by the Lugworm 
Arenicola marina (L.), Environ. Sci. Technol., 47, 593-600.

Chua, E. M., J. Shimeta, D. Nugegoda, P. D. Morrison, and B. O. Clarke (2014), Assimilation of Polybrominated Diphenyl Ethers from Microplastics by the Marine Amphipod, Allorchestes Compressa, Environ. Sci. Technol., 48, 8127-8134.

Endo, S., M. Yuyama, and H. Takada (2013), Desorption kinetics of hydrophobic organic contaminants from marine plastic pellets, Mar. Pollut. Bull., 74(1), 125-131, doi:10.1016/j.marpolbul.2013.07.018.

Gewert, B., M. M. Plassmann, and M. Macleod (2015), Pathways for degradation of plastic polymers floating in the marine environment, Environ. Sci. Process. Impacts, 17, 15131521, doi:10.1039/C5EM00207A.

Gouin, T., N. Roche, R. Lohmann, and G. Hodges (2011), A thermodynamic approach for assessing the environmental exposure of chemicals absorbed to microplastic., Environ. Sci. Technol., 45, 1466-72, doi:10.1021/es1032025.

Herzke, D., T. Anker-nilssen, T. H. Nøst, A. Go, S. Christensen-dalsgaard, M. Langset, K. Fangel, and A. A. Koelmans (2016), Negligible Impact of Ingested Microplastics on Tissue Concentrations of Persistent Organic Pollutants in Northern Fulmars o ff Coastal Norway, , doi:10.1021/acs.est.5b04663.

Hirai, H. et al. (2011), Organic micropollutants in marine plastics debris from the open ocean and remote and urban beaches, Mar. Pollut. Bull., 62(8), 1683-1692, doi:10.1016/j.marpolbul.2011.06.004.

Jambeck, J. R., R. Geyer, C. Wilcox, T. R. Siegler, M. Perryman, A. Andrady, R. Narayan, and K. L. Law (2015), Plastic waste inputs from land into the ocean., Science (80-. )., doi:10.1126/science. 1260352.

Jang, M., W. J. Shim, G. M. Han, M. Rani, Y. K. Song, and S. H. HONG (2016), Styrofoam debris as a source of hazardous additives for marine organisms, Environ. Sci. Technol., acs.est.5b05485, doi:10.1021/acs.est.5b05485.

Karapanagioti, H. K., S. Endo, Y. Ogata, and H. Takada (2011), Diffuse pollution by persistent organic pollutants as measured in plastic pellets sampled from various beaches in Greece., Mar. Pollut. Bull., 62, 312-317.

Koelmans, A. A., E. Besseling, and E. M. Foekema (2014), Leaching of plastic additives to marine organisms, Environ. Pollut., 187, 49-54, doi:10.1016/j.envpol.2013.12.013.

Koelmans, A. A., A. Bakir, G. A. Burton, and C. R. Janssen (2016), Microplastic as a Vector for Chemicals in the Aquatic Environment: Critical Review and Model-Supported Reinterpretation of Empirical Studies, Env. Sci Technol, 50, 3315-3326, doi:10.1021/acs.est.5b06069.

Lavender Law, K., S. Morét-Ferguson, N. A. Maximenko, G. Proskurowski, E. E. Peacock, J. Hafner, and C. M. Reddy (2010), Plastic Accumulation in the North Atlantic Subtropical Gyre, Science (80-. )., 329, 1185-1188, doi:10.1126/science.1192321.

Lohmann, R. (2012), Critical Review of Low-Density Polyethylene's Partitioning and Diffusion Coefficients for Trace Organic Contaminants and Implications for Its Use As a Passive Sampler, Environ. Sci. Technol., 46, 606-618.

Lohmann, R., and D. Muir (2010), Global aquatic passive sampling (AQUA-GAPS): Using passive samplers to monitor POPs in the waters of the world, Environ. Sci. Technol., 44(3), 860-864, doi:10.1021/es902379g.

Moser, G. A., and M. S. McLachlan (1999), A non-absorbable dietary fat substitute enhances elimination of persistent lipophilic contaminants in humans., Chemosphere, 39(9), 1513- 
1521.

Pintado-Herrera, M. G., P. A. Lara-Martín, E. González-Mazo, and I. J. Allan (2016), Determination of silicone rubber and low-density polyethylene diffusion and polymer/water partition coefficients for emerging contaminants, Environ. Toxicol. Chem., 35(9), 21622172, doi:10.1002/etc.3390.

Rochman, C. M., E. Hoh, B. T. Hentschel, and S. Kaye (2012), Long-Term Field Measurement of Sorption of Organic Contaminants to Five Types of Plastic Pellets: Implications for Plastic Marine Debris,

Rochman, C. M., E. Hoh, T. Kurobe, and S. J. Teh (2013), Ingested plastic transfers hazardous chemicals to fish and induces hepatic stress, Sci. Rep., 3, 3263-3269, doi:10.1038/srep03263.

Rochman, C. M., R. L. Lewison, M. Eriksen, H. Allen, A. Cook, and S. J. Teh (2014), Polybrominated diphenyl ethers (PBDEs) in fish tissue may be an indicator of plastic contamination in marine habitats, Sci. Total Environ., 476-477, 622-633, doi:10.1016/j.scitotenv.2014.01.058.

Rusina, T. P., F. Smedes, J. Klanova, K. Booi, and I. Holoubek (2007), Polymer selection for passive sampling : A comparison of critical properties, Chemosphere, 68, 1344-1351, doi:10.1016/j.chemosphere.2007.01.025.

Schwarzenbach, R. P., P. M. Gschwend, and D. M. Imboden (2003), Environmental Organic Chemistry, 2nd ed., Wiley-Interscience, New York.

Sebille, E. Van, C. Wilcox, L. Lebreton, N. Maximenko, B. D. Hardesty, J. Franeker, M. Eriksen, D. Siegel, F. Galgani, and K. L. Law (2015), A global inventory of small floating plastic debris, Environ. Res. Lett., 10(12), 124006, doi:10.1088/1748-9326/10/12/124006.

Smedes, F., R. W. Geertsma, T. Von der Zande, and K. Booij (2009), Polymer - Water Partition Coefficients of Hydrophobic Compounds for Passive Sampling : Application of Cosolvent Models for Validation, Environ. Sci. Technol., 43(18), 7047-7054.

Stapleton, H. M., R. J. Letcher, and Bak (2004), Debromination of Polybrominated Diphenyl Ether Congeners BDE 99 and BDE 183 in the Intestinal Tract of the Common Carp ( yprinus carpio), Env. Sci Technol, 38(4), 1054-1061.

Tanaka, K., H. Takada, R. Yamashita, K. Mizukawa, and M. Fukuwaka (2013), Accumulation of plastic-derived chemicals in tissues of seabirds ingesting marine plastics, Mar. Pollut. Bull., 69(1-2), 219-222, doi:10.1016/j.marpolbul.2012.12.010.

Teuten, E. L., S. J. Rowland, T. S. Galloway, and R. C. Thompson (2007), Potential for Plastics to Transport Hydrophobic Contaminants, Environ. Sci. Technol., 41, 7759-7764.

Teuten, E. L. et al. (2009), Transport and release of chemicals from plastics to the environment and to wildlife, Philos. Trans. R. Soc. B Biol. Sci., 364, 2027-2045, doi:10.1098/rstb.2008.0284.

Thompson, R. C., Y. Olsen, R. P. Mitchell, A. Davis, S. J. Rowland, A. W. G. John, D. McGonigle, and A. E. Russell (2004), Lost at Sea: Where Is All the Plastic?, Science (80-. )., 304(5672), 838 .

UNEP (2001), Final act of the plenipotentiaries on the Stockholm Convention on persistent organic pollutants., Geneva, Switzerland.

Wardrop, P., J. Shimeta, D. Nugegoda, P. D. Morrison, A. Miranda, M. Tang, and B. O. Clarke (2016), Chemical Pollutants Sorbed to Ingested Microbeads from Personal Care Products Accumulate in Fish, Env. Sci Technol, 50, 4037-4044, doi:10.1021/acs.est.5b06280.

Zarfl, C., and M. Matthies (2010), Are marine plastic particles transport vectors for organic 
pollutants to the Arctic ?, Mar. Pollut. Bull., doi:10.1016/j.marpolbul.2010.05.026.

Zhang, L., and R. Lohmann (2010), Cycling of PCBs and HCB in the surface ocean-lower atmosphere of the open pacific, Environ. Sci. Technol., 44(10), 3832-3838, doi:10.1021/es9039852.

Ziccardi, L. M., A. Edgington, K. Hentz, K. J. Kulacki, and S. Kane Driscoll (2016), Microplastics as vectors for bioaccumulation of hydrophobic organic contaminants in the marine environment: A state-of-the-science review, Environ. Toxicol. Chem., 35(7), 16671676, doi:10.1002/etc.3461.

\section{List of Tables and Figures}

- Figure 1 with bioaccumulation set-up

- Table 1: Bioaccumulation studies involving microplastics and POPs

- Table 2: Criteria for inclusion of compounds to the Stockholm Convention on POPs 